at Saint Michael's College, May 13, 2008:

The Case of "Anna" Subjected to Proof

R.B. Miller, M. Kessler, M. Bauer, S. Howell, K. Kreiling, \& M. Miller

Pragmatic Case Studies in Psychotherapy, http://pcsp.libraries. rutgers.edu

Volume 7, Module 1, Article 7, pp. 95-100, 02-28-11 [copyright by authors]

\title{
Findings of the Panel of Psychological Inquiry Convened at Saint Michael’s College, May 13, 2008: The Case of “Anna”
}

\section{RONALD B. MILLER ${ }^{\text {a,g }}$, MARC KESSLER ${ }^{\text {b }}$, MARION BAUER ${ }^{\text {c, }}$ SANDRA HOWELL ${ }^{d}$, KENNETH KREILING ${ }^{e}$, \& MELVIN MILLER ${ }^{f}$}

a Department of Psychology, St. Michael's College, Colchester, VT

b Department of Psychology, University of Vermont, Burlington, VT

${ }^{\mathrm{C}}$ Private Practice, Middlebury, VT

${ }^{\mathrm{d}}$ Private practice, Montpelier, VT and Past-President, Vermont Psychological Association

e Vermont Law School, South Royalton, VT

f Norwich University, Northfield, VT

${ }^{\mathrm{g}}$ Correspondence concerning this article should be addressed to Ronald B. Miller, Department of Psychology, St.

Michael's College, Colchester, VT, 05439

Email: rmiller@smcvt.edu

Note: Portions of this paper were presented at the annual meeting of the International Society for Psychotherapy Research in Barcelona, Spain during June, 2008.

\begin{abstract}
This paper briefly describes the proceedings of the Panel of Inquiry held May 13, 2008 at Saint Michael's College on the case of “Anna" (Podetz, 2008, 2011). It summarizes the advocate's and critic's positions on four claims and one counter-claim. The five judges independently voted to accept all four of the advocate's claims (by votes of 5-0 or 4-1), and rejected the critic's counterclaim by a vote of 3-2. The panelists all found the educative and pedagogical aspects of the Panel of Inquiry process commendable, but several raised questions about how this methodology would be accepted by their own research and practice communities.
\end{abstract}

Key words: Panels of Psychological Inquiry, quasi-judicial method, jury hearing, case study, clinical case study

On May 13, 2008 the “Case of Anna” by Ms. Stacy Podetz (2008, 2011), a second year graduate student in clinical psychology at Saint Michael's College, was presented and critiqued before a five member Panel of Psychological Inquiry. The judges were appointed by Ronald B. Miller, Ph.D., director of the Graduate Program in Clinical Psychology at the College, who presided over the Panel meeting. The judges were: Marion Bauer, M.Ed., licensed in Vermont for over 30 years as both a school guidance counselor and clinical psychologist with over 10 years experience as a member of the Vermont Psychological Association (VPA) Ethics Committee; Sandra Howell, M.A., a clinician with over 25 years experience in the practice of school psychology and psychotherapy and at the time of the hearing, president of the Vermont Psychological Association; Marc Kessler, Ph.D., professor of psychology emeritus, University of 
Findings of the Panel of Psychological Inquiry Convened

at Saint Michael's College, May 13, 2008 :

The Case of "Anna" Subjected to Proof

R.B. Miller, M. Kessler, M. Bauer, S. Howell, K. Kreiling, \& M. Miller

Pragmatic Case Studies in Psychotherapy, http://pcsp.libraries. rutgers.edu

Volume 7, Module 1, Article 7, pp. 95-100, 02-28-11 [copyright by authors]

Vermont department of psychology, who taught, trained clinicians, and practiced psychotherapy for over 35 years; Melvin Miller, Ph.D., the Dana Professor of Psychology at Norwich University where he had also been for the past 25 years the director of their Counseling and Psychotherapy Service; and Ken Kreiling, JD, LLM, a professor of law at the Vermont Law School for over 30 years, specializing in civil procedure and the evaluation of scientific evidence.

Stacy Podetz $(2008,2011)$ was both the therapist in the case study and its author. Several weeks prior to the meeting, she submitted a rough draft of her case-study master's thesis paper (Podetz, 2008) to the judges and other participants. The 75 page paper included a description of the case as well as over 20 citations to the relevant case, theoretical, and empirical literature on psychodynamic and humanistic approaches to the therapy of self-harming behavior. Ms. Podetz summarized the case of 'Anna” in the paper's abstract in the following manner:

The client, Anna, provides an interesting case of an 18 year-old girl who has a six-year history of self-injury, panic attacks, anxiety and depression. She presented with a unique pattern of cutting in which she would cut when she felt too much and when she didn't feel enough... Her thousands of scars are a testament to her deep emotional pain, which are each associated with her relationship with her parents. From a psychodynamic perspective, Anna has presented as very defended as she often suppresses her emotions, idealizes her father, and dissociates during cutting episodes. The therapy primarily focused on maintaining and fostering the therapeutic relationship while using transference and countertransference issues in order to promote the growth and understanding of her deeply rooted pain. (Podetz, 2008, p. 4)

At the Panel of Inquiry meeting Ms. Podetz's case was presented to the judges by a case advocate, Ms. Alexandra Altman, who was opposed by the case critic, Jess DiGiorgianni, PhD, both of whom are not only second year graduate students in the Saint Michael's clinical psychology program, but also individuals who were highly accomplished in other careers prior to entering the program. In addition to hearing arguments for and against the case by the advocate and critic, the Panel heard testimony from both Ms. Podetz and her clinical supervisor, Ms. Andrea Kelly, MA, the director of the college counseling center where Ms. Podetz did her internship. Both were questioned by the case advocate, critic, and judges. During the questioning, the judges also were free to question the advocate or the critic. In the process, the judges also reviewed five documents submitted into evidence during the Inquiry: the general case study consent form authorizing the use of confidential information in the case narrative; the consent form for use of the case study material in a Panel of Inquiry meeting; the client intake form as filled out by Anna; a sample of Anna's creative writing; and the supervisor's curriculum vitae.

The case advocate, Alexandra Altman, presented arguments to prove four claims derived from the case study narrative:

Claim One. Without reservation, it is absolutely clear that the patient, "Anna,” presented with a serious psychopathology. 
Findings of the Panel of Psychological Inquiry Convened

at Saint Michael's College, May 13, 2008 :

The Case of "Anna" Subjected to Proof

R.B. Miller, M. Kessler, M. Bauer, S. Howell, K. Kreiling, \& M. Miller

Pragmatic Case Studies in Psychotherapy, http://pcsp.libraries. rutgers.edu

Volume 7, Module 1, Article 7, pp. 95-100, 02-28-11 [copyright by authors]

Claim Two. It is clear that Stacey, the therapist, provided humanistic, psychodynamically informed therapy to "Anna."

Claim Three. This case demonstrates the capacity of a first year intern to be demonstrably useful in providing therapy to clients in a counseling center, as we maintain that it is highly probable that the treatment resulted in increased health and growth.

Claim Four. Stacey's premise, that “Anna's” cutting served a self-regulatory function as it offered relief from the tension of both numbness and excessive anxiety, was valid and critical to the client's eventual growth.

While acknowledging the caring and compassionate work done in this case, the case critic, Dr. Jess DiGiorgianni, challenged Ms. Podetz's understanding of the case by arguing that the therapist's feelings of an intense desire for the client to improve and stop cutting constituted a countertransference that interfered with a thorough-going understanding and treatment of the case. This therefore calls into question the completeness or accuracy of each of the four claims. Essentially, the critic argued that the client's unexamined anger at her mother, self-disgust, and attempts to comply with Ms. Podetz's desire for her to engage in less self-injurious behavior, constitute evidence that the psychopathology in the case may have been more severe than described, the therapy insufficiently depth-oriented, the outcome less permanent than supposed, and the interpretation of cutting as self-regulating as too superficial.

\section{THE JUDGES' OPINION}

After careful deliberation, each of the judges submitted an independent evaluation of the claims and counterclaims that included the identification of the reasons for their acceptance or rejection of each claim. Reasons given tended to focus on the details of the clinical case, persuasiveness of the evidence, or the clarity of the argument made by the advocate or critic. It was clear that while the judges' various theoretical or professional backgrounds did influence their judgments on the truth of the various claims, it seemed in most instances to alter the strength of their conviction as opposed to the direction of their judgments. In other words, it seemed that the power of the case material influenced whether they accepted or rejected the claims, but the degree of intensity with which they held their positions was tempered by theoretical presuppositions. This is akin to judges in the law writing about how the facts of a case can take hold and over-ride a liberal or conservative predisposition.

\section{Claim One}

By a vote of 5-0 the judges voted to accept the advocate's first claim that Anna's psychological problems were representative of severe psychopathology. The judges found the preponderance of evidence and testimony was in favor of this claim. One of the judges suggested that a more accurate term might have been "moderate-severe" psychopthology. The judges were influenced by the therapist's careful description of the client's current circumstances, life history, and in-session behavior. They found the therapist's knowledge of the literature on working with 
Findings of the Panel of Psychological Inquiry Convened

at Saint Michael's College, May 13, 2008:

The Case of "Anna" Subjected to Proof

R.B. Miller, M. Kessler, M. Bauer, S. Howell, K. Kreiling, \& M. Miller

Pragmatic Case Studies in Psychotherapy, http://pcsp.libraries. rutgers.edu

Volume 7, Module 1, Article 7, pp. 95-100, 02-28-11 [copyright by authors]

young women who cut and the supervisor's experience with this problem in a college population supported the credibility of the clinical assessment.

\section{Claim Two}

By a vote of 4-1 the judges found that the preponderance of evidence supported the claim that the therapist had offered a form of therapy based upon a blend of humanistic and psychodynamic principles. One of those voting with the majority also expressed some reservation that the blend of approaches had too heavily favored the humanistic approach, while another found the blend somewhat inexact and confusing. This is not very different from the explanation given by the judge that voted against accepting the claim because of it's lack of clarity. This suggests that while the claim was accepted, the confidence in the claim was tempered because of the ambiguity of the theoretical terms contained therein, and the vagueness of the claim itself.

\section{Claim Three}

By a vote of 5-0 the judges found that a preponderance of evidence supported the claim that a psychology intern had offered psychotherapy in a difficult case that resulted in emotional growth and increased psychological health. One of those voting expressed a reservation that the therapy might have been even more efficacious had the interpretations offered been less hampered by the therapist's countertransference, specifically her need to both be liked by the client and to see the client succeed in therapy. Two of the judges explicitly noted that the therapist's manner of testifying about the client-therapist relationship was compelling and convincing. They found her account of the work done as essentially believable, and this was further corroborated by the credibility of the supervisor's detailed knowledge and close supervision of this case. The supervisor's testimony about her own training in dealing with college students who engage in cutting, and her belief there had been a real shift toward health in the client over the course of two semesters, further reinforced the impression that the therapist's account of the work was realistic and credible.

This finding is similar to the judges' view of Claim One on the degree of psychopathology that was much more strongly supported than Claim Two about the type of therapy being conducted. This leaves us in the somewhat anomalous position of holding that a quite severe problem was aided in psychotherapy even though it is not entirely clear what to call the form of therapy offered.

\section{Claim Four}

By a vote of 5-0 the judges accepted the claim that the interpretation of cutting as selfregulatory was instrumental in the promoting of the health of the client. Two of the judges expressed a reservation noting that the interpretation while accurate was probably not complete, and did not deal sufficiently with the client's anger at her mother, the therapist, and the selfhatred that results from this anger. This finding is of note in that it is the most specific theoretical claim as to what exact psychological process was responsible for the main symptom of cutting, and what exact process in therapy was curative, namely, the interpretation of cutting as a defense 
Findings of the Panel of Psychological Inquiry Convened

at Saint Michael's College, May 13, 2008:

The Case of "Anna" Subjected to Proof

R.B. Miller, M. Kessler, M. Bauer, S. Howell, K. Kreiling, \& M. Miller

Pragmatic Case Studies in Psychotherapy, http://pcsp.libraries. rutgers.edu

Volume 7, Module 1, Article 7, pp. 95-100, 02-28-11 [copyright by authors]

that regulates affect. While the judges almost rejected the theoretical claim in Claim Two, they were unanimous in accepting Claim Four.

\section{Counterclaim}

The judges voted 3-2 to reject the critic's counterclaim that the therapist's countertransference undermined the completeness or accuracy of each of the advocate's claims. One of those in the majority did nonetheless express a belief that the critic's view of countertransference in the case was valid in that counter-transference probably played a bigger part in the treatment decisions than the advocate or author were prepared to admit. However, this judge thought the claims had been framed in such a manner as to leave open the possibility that more work might still need to be done to address the deeper layers of the client's problems, and so the critic's points, while well taken, did not refute the rather limited claims that were actually made about the nature of the symptoms or the success of the interpretations or treatment. Given how close that is to the view of the minority, one might conclude that the panel was essentially deadlocked in their view of the counterclaims.

Two of the judges expressed concern that the critic's choice of a dialectical approach to his role was problematic, and that the role of the critic needs to be more adversarial, with the critic's positions more sharply distinguished from those taken by the advocate. On the other hand, two of the other judges expressed appreciation for the collegial fashion in which the Panel was conducted and how the role of the critic was performed, and thought it important that therapists feel supported in the process or they might avoid such an opportunity to look critically at their own work.

\section{REFLECTION ON THE PANEL PROCESS}

In responding to a question about their overall assessment of the experience of serving on the Panel, all five judges thought that the process of the Panel of Inquiry was an excellent learning experience for the trainees involved in terms of learning to think critically about case material. They were impressed with the capacity of the graduate students to carry out their roles in the Panel of Inquiry hearing. Several suggested that they would like to see their own students or trainees engage in such an inquiry, though they wondered whether students would be generally willing to publicly critique another student's clinical work. The academic psychologists found the methodology innovative, but so different from their own view of validating clinical claims that they wondered whether the field would accept the approach, and could see reasons why both psychoanalytic practitioners and experimental psychologists would object to the process as either too intrusive (in the case of the analysts) or too subjective (in the case of the experimentalists). The first author observed that any methodology upon which both the psychoanalysts and the experimentalists might agree must certainly have merit! 


\section{REFERENCES}

Miller, R.B. (2011). Real Clinical Trials $\left(\mathrm{RCT}^{1}\right)$ - Panels of Psychological Inquiry for transforming anecdotal data into clinical facts and validated judgments: Introduction to a pilot test with the case of “Anna.” Pragmatic Case Studies in Psychotherapy, 7(1), Article 2, 6-36. Available: http://hdl.rutgers.edu/1782.1/pcsp_journal

Podetz, S. (2008) Seeing beyond the scars: A case study of “Anna.” Unpublished master's thesis in psychology. St. Michael's College: Colchester, Vermont.

Podetz, S. (2011). Seeing beyond the scars: A testament to “Anna.” Pragmatic Case Studies in Psychotherapy, 7(1), Article 3, 37-63. Available:

http://hdl.rutgers.edu/1782.1/pcsp_journal

Note: After the Panel of Inquiry described in Miller (2011) was completed, Podetz's masters thesis was reformatted and copyedited to meet the guidelines of a PCSP case study, and some of the broader literature review was shortened. Aside from these two differences, the substance of Podetz's 2008 and 2011 versions of the case study of Anna are identical. 